\title{
Natural History of a Transitional Atrioventricular Septal Defect in an Adult Patient with Down Syndrome
}

\author{
Mara Escudero-Salamanca1,2, Nilda Espinola-Zavaleta ${ }^{1,3 *}$ \\ ${ }^{1}$ Nuclear Cardiology Department, National Institute of Cardiology Ignacio Chavez, Mexico City, Mexico \\ ${ }^{2}$ Mexican Faculty of Medicine, La Salle University, Mexico City, Mexico \\ ${ }^{3}$ Department of Echocardiography, ABC Medical Center, I.A.P, Mexico City, Mexico \\ Email: *niesza2001hotmail.com
}

How to cite this paper: Escudero-Salamanca, M. and Espinola-Zavaleta, N. (2021) Natural History of a Transitional Atrioventricular Septal Defect in an Adult Patient with Down Syndrome. World Journal of Cardiovascular Diseases, 11, 342-346.

https://doi.org/10.4236/wjcd.2021.117033

Received: June 15, 2021

Accepted: July 11, 2021

Published: July 14, 2021

Copyright $\odot 2021$ by author(s) and Scientific Research Publishing Inc. This work is licensed under the Creative Commons Attribution International License (CC BY 4.0).

http://creativecommons.org/licenses/by/4.0/

(c) (i) Open Access

\begin{abstract}
Background: Atrioventricular septal defects (AVSD) are caused by a lack of development in atrioventricular endocardial cushions. Its spectrum varies from partial to transitional, or intermediate forms with a common AV valve and 2 orifices, or even the complete form. Aim: The aim of this study is to present a case of a woman in the fifth decade of life with Down syndrome and a transitional AVSD, diagnosed with echocardiography. Case presentation: This is a patient in the fifth decade of life with Down syndrome, transitional AVSD, and severe pulmonary hypertension. Her vital signs were normal, oxygen saturation of $89 \%$ on room air. Auscultation revealed pronounced pulmonary component of the second heart sound, diastolic murmur in second left intercostal space, and moderate holosystolic heart murmur that radiated to axilla. The diagnosis was made with a transthoracic echocardiogram. The patient is receiving only medical treatment and since her last consult she has New York Heart Association (NYHA) functional class II. Conclusion: This case demonstrates the natural history of a patient in her fifth decade of life with down syndrome and complex congenital heart disease, despite having received only medical treatment, she is in functional class II. Echocardiography is the noninvasive technique of choice in the diagnosis and follow-up of patients with congenital heart diseases, as seen in this case.
\end{abstract}

\section{Keywords}

Transitional Atrioventricular Septal Defect, Pulmonary Hypertension, Echocardiography 


\section{Introduction}

The incidence of atrioventricular septal defects (AVSD) is estimated to be between 0.24 to $0.31 / 1000$ live births and has a strong association with Down syndrome (DS), with an incidence of $40 \%$ to $50 \%$ [1] [2].

Atrioventricular septal defects (AVSD) are caused by a lack of development in atrioventricular endocardial cushions, which do not fuse, causing a malformation in the atrioventricular (AV) septum. Its spectrum varies from partial to transitional, or intermediate forms with a common AV valve and 2 orifices, or even the complete form [1]. In transitional and intermediate AVSD, there is a single AV junction with two AV valves. The left AV valve is trifoliate, embryologic fusion of upper and lower leaflets originate the so-called "cleft" which is the point of apposition between the two bridging leaflets. It generally causes varying degrees of valve regurgitation, and stenosis in rare occasions. Transitional AVSD is uncommon in adults, with diagnosis made by echocardiography [3].

The echocardiogram in its different modalities provides precise morphological and hemodynamic data for the diagnosis and monitoring of this complex congenital heart disease (CHD).

\section{Case Presentation}

This is the case of a 48-year-old female with diagnosis of Down syndrome and complex congenital heart disease (CHD). Since birth, she was diagnosed with atrioventricular septal defect, at the age of 3 months, she presented cyanosis and hypoxemia, but her family refused the suggested surgical treatment. In adulthood, she was referred to our institution, due to exertional dyspnea and dizziness of six months of evolution. Her vital signs were normal, and oxygen saturation of $89 \%$ on room air. Auscultation revealed pronounced pulmonary component of the second heart sound, diastolic murmur in second left intercostal space, and holosystolic heart murmur grade IV/IV radiated to axilla, lung sounds were clear. There was no hepatomegaly, extremities had good circulation with no evidence of clubbing or cyanosis.

Electrocardiogram showed sinus rhythm with heart rate of $79 \mathrm{bpm}$, bi-atrial and biventricular enlargement. Transthoracic echocardiogram (TTE) demonstrated dilation of the four chambers and unbalanced ventricles with normal systolic ventricular function with left ventricular ejection fraction of $67 \%$, global longitudinal deformation of $-27.1 \%$, TAPSE of $17 \mathrm{~mm}$ and $S$ wave of $10 \mathrm{~cm} / \mathrm{s}$. The systolic pulmonary artery pressure calculated by tricuspid regurgitation method and right atrial pressure was $93 \mathrm{mmHg}$. The color Doppler showed an ostium secundum atrial septal defect (OP-ASD) with a bidirectional shunt, restrictive small inlet-ventricular septal defect (I-VSD), right-sided moderate AV regurgitation and left-sided severe AV regurgitation with two jets probably due to a cleft in the anterior leaflet. A diagnosis of transitional AVSD was made, (Figure 1, Video 1). 


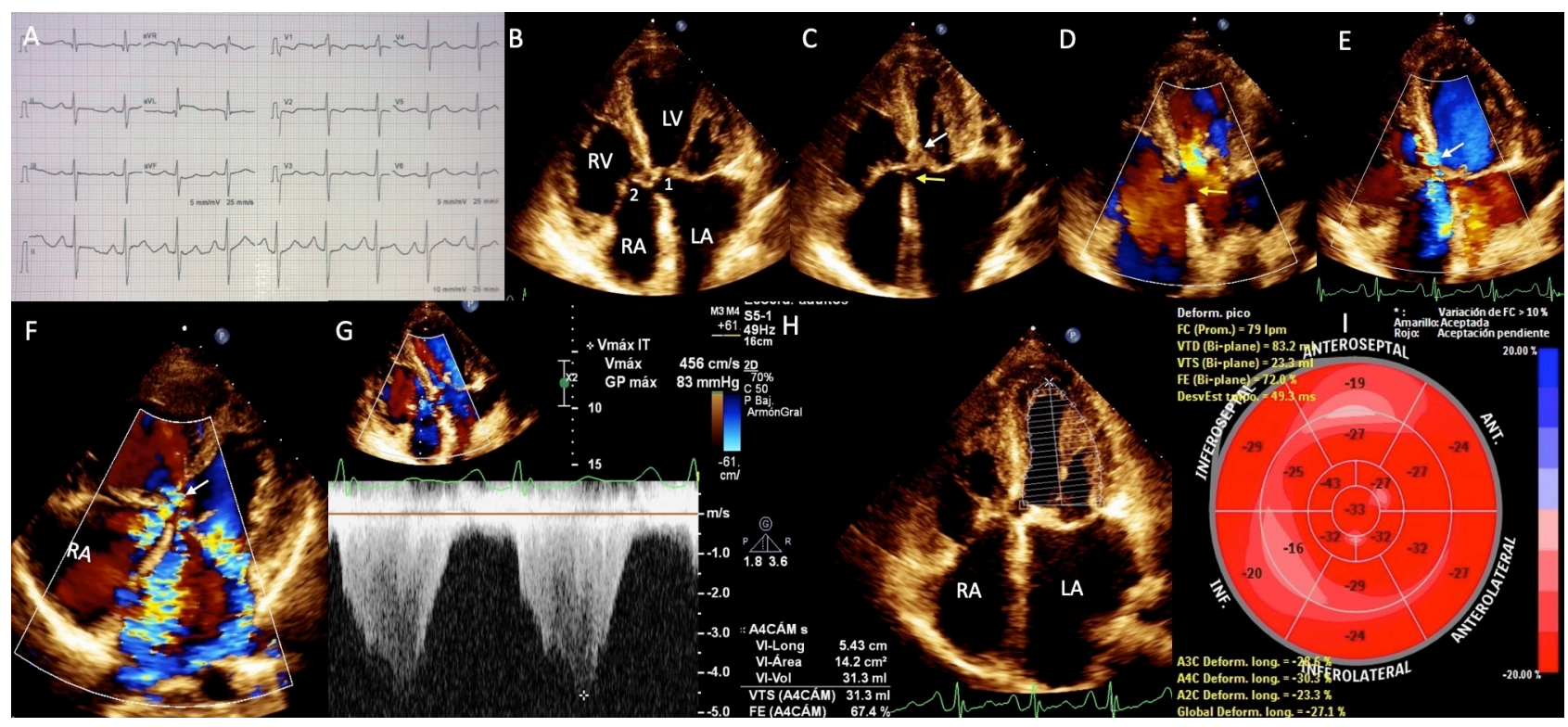

Figure 1. (A) ECG in sinus rhythm with heart rate $79 \mathrm{bpm}$, and biatrial and biventricular enlargement. (B) Bidimensional transthoracic echocardiography in four chamber view showing transitional AVSD, AV valve with two separate orifices $(1,2)$. (C, video 1) with ostium primum atrial septal defect (yellow arrow) and insertion of the anterior septal leaflet in the crest of interventricular septum (white arrow). (D) with color Doppler the ostium primum atrial septal defect is clearly visualized (yellow arrow). (E) also the restrictive inlet-ventricular septal defect (white arrow) and right sided atrioventricular regurgitation, (F) right-sided moderate and left-sided severe regurgitation (two jets) of atrioventricular valves and restrictive inlet-ventricular septal defect (white arrow). (G) four chamber view with color Doppler and continuous wave showing pulmonary hypertension (PH) with systolic pulmonary artery pressure of $93 \mathrm{mmHg}$. $(\mathrm{H})$ dilation of the four chambers with normal left ventricular ejection fraction (67\%) and (I) normal global longitudinal deformation (-27\%). Abbreviations: RA: right atrium; RV: right ventricle; LA: left atrium; LV: left ventricle; 1 : left-sided atrioventricular valve; 2 : right-sided atrioventricular valve.

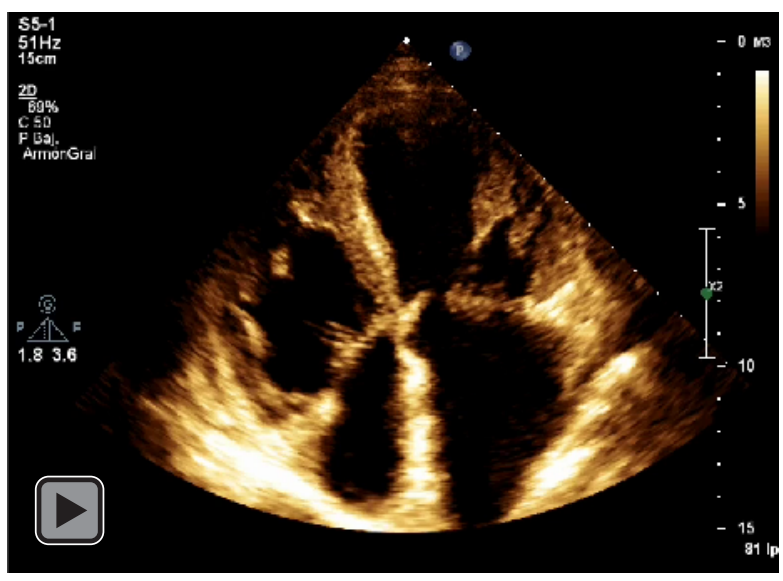

Video 1. Four chamber view showing transitional AVSD, AV valve with two separate orifices, ostium primum atrial septal defect and insertion of the anterior septal leaflet in the crest of interventricular septum.

The patient receives treatment with sildenafil $100 \mathrm{mg}$ every 24 hours, furosemide $40 \mathrm{mg}$ every 24 hours and oxygen at night 2 liters/min. She has NYHA functional class II, with follow-up every 3 months in the outpatient clinic for adult congenital heart disease. 


\section{Discussion}

Our case highlights the value of echocardiography in the diagnosis and follow-up of this CHD. It is important to mention that this patient with Down syndrome, despite her complex CHD, chronic dyspnea (shortness of breath lasting more than 1 month) and pulmonary hypertension, is in a suitable NYHA functional class, receiving only medical treatment with almost no impairment in her daily life.

The AVSD involves alterations of the atrioventricular valves, the ventricular geometry, the fibrous skeleton, and the conduction system. There is a wide spectrum of insertion of the left anterior leaflet (bridge leaflet) that includes intermediate sites.

Van Praagh and Litovsky classification distinguishes intermediate AVSD from transitional AVSD, which has two separate AV valve rings, an ostium primum ASD and a cleft in the mitral valve, and there are often one or more small inlet VSDs that could be restricted or obliterated by dense cords running from the AV valves to the crest of the muscular ventricular septum [4].

The morphological knowledge of the AVSD is essential to understand its pathophysiology, establish clinical diagnosis by imaging techniques and provide surgical team with valuable information to choose strategies [5].

The treatment of choice for patients with Down syndrome and transitional AVSD is commonly heart surgery [6].

Approximately, 15\% of patients with unrepaired AVSD and Down syndrome may develop atrial arrhythmias, heart failure, or infrequently Eisenmenger phenomenon during adulthood. Therefore, these patients require lifelong surveillance to identify late-onset complications, which depend on the size of the ASD, competence of the left atrio-ventricular valve, pulmonary artery pressure, and pulmonary vascular resistance [7].

Due to the continuing increase in life expectancy, elderly Down syndrome patients with congenital heart disease, should receive appropriate counseling regarding medical and surgical therapy.

\section{Conclusions}

Our case is particularly interesting, since it demonstrates the natural history of a patient in her fifth decade of life with Down syndrome and complex congenital heart disease, who despite having received only medical treatment, has NYHA functional class II in her clinical follow-ups.

Echocardiography is the noninvasive technique of choice in the diagnosis and follow-up of patients with complex CHD.

\section{Acknowledgement Section}

Permission for presentation has been obtained from patient's mother.

\section{Ethical Standards}

The authors assert that all procedures contributing to this work comply with the 
ethical standards of the relevant national guidelines on human experimentation and with the Helsinki Declaration of 1975, as revised in 2008, and has been approved by the institutional committees (National Institute of cardiology Ignacio Chavez).

\section{Conflicts of Interest}

The authors declare no conflicts of interest regarding the publication of this paper.

\section{References}

[1] Sheffield, E.M., Sterk, A.J., Samuel, B.P. and Cook, S.C. (2020) Unrepaired Transitional Atrioventricular Septal Defect in a Geriatric Woman with Down Syndrome. Case Report. SN Comprehensive Clinical Medicine, 2, 2479-2481.

https://doi.org/10.1007/s42399-020-00579-4

[2] Nayak, S., Kanakriyeh, M. and Varadarajan, P. (2020) Echocardiographic Assessment of Atrioventricular Canal Defects. Echocardiography, 37, 2199-2210. https://doi.org/10.1111/echo.14961

[3] De Angelis, F., Savino, K., Colombo, A., Sardone, M. and Ambrosio, G. (2019) Never Too Grown-Up for a Congenital Heart Disease: Diagnosis of Transitional Atrioventricular Canal in a 50-Year-Old Male. Journal of Cardiovascular Echography, 29, 35-38. https://doi.org/10.4103/jcecho.jcecho $28 \quad 18$

[4] Van Praagh, R. and Litovsky, S. (1999) Pathology, and Embryology of Common Atrioventricular Canal. Progress in Pediatric Cardiology, 10, 115-127. https://doi.org/10.1016/S1058-9813(99)00025-9

[5] Kuri-Nivon, M., Martinez-Martinez, E., Muñoz-Castellanos, L. and Espinola-Zavaleta, N. (2008) Atrioventricular Septal Defect. Anatomopathologic Study and Embryological Correlation. Archivos de Cardiología de México, 78, 19-29.

[6] Irving, C.A. and Chaudhari, M.P. (2012) Cardiovascular Abnormalities in Down's Syndrome: Spectrum, Management, and Survival over 22 Years. Archives of Disease in Childhood, 97, 326-330. https://doi.org/10.1136/adc.2010.210534

[7] Waqar, T., Riaz, M.U. and Shuaib, M. (2017) Surgical Repair of Partial Atrioventricular Septal Defect. Pakistan Journal of Medical Sciences, 33, 285-289.

https://doi.org/10.12669/pjms.332.12094 